\title{
Session-RPE Method for Training Load Monitoring: Validity, Ecological Usefulness, and Influencing Factors
}

OPEN ACCESS

Edited by: Raffaella Franciotti, Università degli Studi "G. d'Annunzio"

Chieti-Pescara, Italy

Reviewed by:

Pablo De Gracia,

Midwestern University, United States

Alena Žákovská,

Masaryk University, Czechia

*Correspondence:

Monoem Haddad

mhaddad@qu.edu.qa

Specialty section: This article was submitted to

Perception Science, a section of the journal Frontiers in Neuroscience

Received: 16 December 2016 Accepted: 19 October 2017 Published: 02 November 2017

Citation: Haddad M, Stylianides G, Djaoui L, Dellal A and Chamari K (2017)

Session-RPE Method for Training Load Monitoring: Validity, Ecological Usefulness, and Influencing Factors.

Front. Neurosci. 11:612.

doi: 10.3389/fnins.2017.00612

\author{
Monoem Haddad ${ }^{1 *}$, Georgios Stylianides ${ }^{2}$, Leo Djaoui ${ }^{3}$, Alexandre Dellal ${ }^{4}$ and \\ Karim Chamari ${ }^{5}$
}

${ }^{1}$ Sport Science Program, College of Arts and Sciences, Qatar University, Doha, Qatar, ${ }^{2}$ Exercise Science Program, Health Professions, Lebanon Valley College, Annville, PA, United States, ${ }^{3}$ Inter-University Laboratory of Human Movement Biology, University of Lyon, University Claude Bernard Lyon1, Lyon, France, ${ }^{4}$ FIFA Medical Centre of Excellence, Centre Orthopédique Santy, Lyon, France, ${ }^{5}$ Athlete Health and Performance Research Centre, ASPETAR, Qatar Orthopaedic and Sports Medicine Hospital, Doha, Qatar

Purpose: The aim of this review is to (1) retrieve all data validating the Session-rating of perceived exertion (RPE)-method using various criteria, (2) highlight the rationale of this method and its ecological usefulness, and (3) describe factors that can alter RPE and users of this method should take into consideration.

Method: Search engines such as SPORTDiscus, PubMed, and Google Scholar databases in the English language between 2001 and 2016 were consulted for the validity and usefulness of the session-RPE method. Studies were considered for further analysis when they used the session-RPE method proposed by Foster et al. in 2001. Participants were athletes of any gender, age, or level of competition. Studies using languages other than English were excluded in the analysis of the validity and reliability of the session-RPE method. Other studies were examined to explain the rationale of the session-RPE method and the origin of RPE.

Results: A total of 950 studies cited the Foster et al. study that proposed the session RPE-method. 36 studies have examined the validity and reliability of this proposed method using the modified CR-10.

Conclusion: These studies confirmed the validity and good reliability and internal consistency of session-RPE method in several sports and physical activities with men and women of different age categories (children, adolescents, and adults) among various expertise levels. This method could be used as "standing alone" method for training load (TL) monitoring purposes though some recommend to combine it with other physiological parameters as heart rate.

Keywords: perceived exertion, training sessions, competitions, individual sports, team sports

\section{INTRODUCTION}

Using a valid and reliable practical tool is imperative for monitoring the training load (TL) imposed on the athlete during every training session. That would assure the optimal adaptation to training before the competition and also reduce the risks of overtraining. Several methods have been proposed to monitor the TL. Foster et al. (2001) proposed a method based on Rating of Perceived Exertion (RPE). This method, known as session-RPE method, takes into consideration both the 
intensity and the duration of a training session. The present review is proposed to assure a best understating of this method and its usefulness for monitoring training in athletes. Therefore, the objective of this review is to (1) Retrieve the literature validating the Session-rating of RPE-method using various criteria, (2) Highlight the rationale of this method and its ecological usefulness, and (3) Describe factors that can alter RPE that end-users of this method should take into consideration.

Search engines such as SPORTDiscus, PubMed, and Google Scholar databases, for the time period ranging between 2001 and 2016 were consulted for the validity and usefulness of the session-RPE method. Studies were considered for further analysis when they used the session-RPE method proposed by Foster et al. (2001). Participants were athletes of any gender, age, or level of competition. Studies using languages other than English were excluded in the analysis of the validity and reliability of the session-RPE method. Other studies were examined to explain the rationale of the session-RPE method and the origin of RPE.

\section{SESSION-RPE METHOD: RATIONALE}

The session-RPE method takes into consideration the intensity and the duration of the training session (or competition) to calculate the TL or competition load. The session-duration refers to the length of session expressed in minutes. A nominal score is given by an athlete to describe his RPE of "mean training intensity" during that training session or competition. Indeed, this method is not only valid for assessing the load relative to training sessions, but also to competition (with some practical issues for some competitions where it is not easy to set the exposure, e.g., team sports where changes are not limited, and therefore, each player's exposure is not easy to assess). For practicality reasons "Training Load" is used in the rest of the paper, but being aware that this is quite reductive as competition is also included.

Basically, the athlete should answer a simple question: "How was your workout?" using the RPE scale. Foster et al. (2001) have modified the verbal anchors used in the CR-10 scale (Borg, 1962) to reflect the American idiomatic English (e.g., light becomes easy; strong or severe becomes hard). According to Foster et al. (2001) rating 6, 8, 9 is not expressed. This single number provided retrospectively by the athlete, refers to the mean intensity of the entire exercise session. Table 1 presents the CR-10 modified by Foster et al. (2001). The athlete should be familiarized with this scale according to standard procedures (Foster et al., 2001) before beginning to collect reliable measures. The origin of the RPE is explained in the following paragraph.

A single arbitrary unit representing the magnitude of global TL for each session is then calculated by the multiplication of training intensity and the length of training (mins). Example: for a session of $87 \mathrm{~min}$, with RPE of 4 (quite hard), the calculations: $87 \times 4$ will provide a TL of 348 A.U. (Arbitrary Units).

$$
\mathrm{TL}(\text { A.U. })=\mathrm{RPE} \mathrm{x} \text { session duration }(\mathrm{min}) \text {. }
$$

TABLE 1 | The modified CR-10 scale by Foster et al. (2001).

\begin{tabular}{ll}
\hline Rating & Descriptor \\
\hline 0 & Rest \\
1 & Very, Very Easy \\
2 & Easy \\
3 & Moderate \\
4 & Somewhat Hard \\
5 & Hard \\
6 & \\
7 & Very Hard \\
8 & \\
9 & \\
10 & Maximal \\
\hline
\end{tabular}

Where: TL is Training Load; A.U. is Arbitrary Units; RPE is Rating of RPE.

\section{RPE: ORIGIN AND ELUCIDATION}

Since the late 1950's, the concept of RPE in sport and exercise science (also known as the sense of effort or perception of effort) has been the subject of increasing thoughtfulness in the scientific literature (Borg, 1962). It has been defined as the conscious sensation of how hard, heavy, and strenuous a physical work is. Its neurophysiological bases are poorly understood despite its importance and usefulness to monitor and prescribe exercise intensity. Some physiologists investigating central regulation of exercise (Proske, 2005; Dempsey et al., 2008) proposed a popular model in which the sense of effort results from the complex integration of different inputs to the central nervous system. Afferent feedback from the peripheral organs (i.e., skeletal muscles, heart, and lungs) and other interceptors (e.g., knowledge of the exercise work endpoint) might be examples of these inputs. Scientists are still continuing their investigations and debates (back $>150$ years) about the origin of RPE and its dependency on efferent and/or afferent sensory signals. Some researchers proposed a corollary discharge model of RPE where the sense of effort (somatosensory areas) is independent from the skeletal muscles, heart, and lung responses. This model confirms that the narrower definition of exertion as "the effort expended in performing a physical activity" (Oxford Dictionary of Sports Science and Medicine) is physiologically suitable. This might be a good explanation of the verbal descriptors chosen by Borg in 1962 and then Foster in 2001 for their RPE scales (Borg, 1962; Foster et al., 2001). Actually, they used "heavy/hard" and "light/easy" rather than "pleasant/unpleasant," "feeling good/ feeling bad," "comfortable/uncomfortable") as ratings of hedonistic (Marcora, 1985). This proposal was confirmed by a sophisticated experiment conducted by Pollak et al. (2014). The results of the latter study showed that metabolite concentrations injected into skeletal muscle in rested state evoked pain-unrelated (e.g., pressure-, movement-, and thermal-related sensations) and pain-related (i.e., ache) sensations. These concentrations of metabolites stimulated muscle afferents similar to what have 
been shown during exercise, while the participants reported no perception of effort. It is then clear that injection of metabolites into skeletal muscle at rest does not generate an increase of effort sensation which is the most important feature of fatigue occurring throughout exercise (Barry and Enoka, 2007). This conclusion is in-line with some previous studies (Hamilton et al., 1985; Marcora, 1985) showing that humans are able to distinguish between sensations of pain and sensation of effort during exercise.

\section{SESSION-RPE METHOD: DERIVED SIMPLE CALCULATIONS}

The "monotony" and "strain" indexes can also be calculated from session-RPE method data of a training microcycle. Actually, the training monotony is a measure of day-to-day training variability that has been found to be related to the onset of overtraining when monotonous training is combined with high TLs (Foster, 1998). Training monotony is calculated using the following formula:

$$
\text { Monotony }=\text { weekly mean TL/SD }
$$

Where weekly mean TL is the average daily TL during the week and SD is the standard deviation of the daily TL calculated over a week.

Another score that might be a useful unit for monitoring training when players are undertaking high TLs is the training strain. This variable is equal to the multiplication of the weekly TL and the monotony scores. Recovery only becomes fundamental to training when high TLs are being undertaken therefore the calculation of training strain appears advantageous. For example, when TLs are high and there has been low variability of load (resulting in a high monotony index), the training strain is high. This type of training has been associated with incidence of illness and poor performance (Putlur et al., 2004). Conversely, training strain is low when players complete either high or low TLs with regular variation in load sessions (i.e., low monotony). In general, high levels of training strain are usually only reached during the preparation period of training when there is no regular competition.

$$
\text { Training strain }=\text { Weekly TL } \mathrm{x} \text { monotony }
$$

Spreadsheets can be used to facilitate the calculation of these scores within team and individual athletes. These scores are quite important to allow an optimal periodization of the training as described below.

\section{SESSION-RPE METHOD: VALIDITY AND RELIABILITY}

With the development of the microtechnologies, many devices are henceforth widely used in the sport industry to monitor TL. Heart rate (HR) monitors, global positioning systems (GPS), accelerometers and wearable body metrics might be some examples of these microtechnologies that can provide coaches with very detailed information on the external (e.g., distance, steps, speed) and internal (e.g., HR, real time electrocardiography, HR variability) TL related variables to be quantified in training sessions.

Although they have the ability to track precise information, these devices have several limitations such as expensive cost, the requirement of high technical expertise and the risk of losing data due to technical error. In addition, these data are quite complex and most of all, to the best of the authors' knowledge, no method has yet worked on getting one single value for a training session TL.

The session-RPE method seems to be a very interesting solution and it has been proposed as a simple, non-invasive and inexpensive method for monitoring TL. The use of the sessionRPE method as a practical tool is led by its strong correlations with selected objective methods described above in different types of training.

Actually, the session-RPE method was mainly proposed by Foster et al. (2001) as a simple system to monitor TL of several training modalities. Since 2001 to December, 17th, 2016, this method has been used in 950 studies (PubMed, SPORTDiscus and Google Scholar Search). Most of these studies focused on the validity of the session-RPE method during several technical and tactical sessions of individuals (Minganti et al., 2010; Haddad et al., 2011a,b, 2013a, 2014a; Rodriguez-Marroyo et al., 2012; Tabben et al., 2013; Padulo et al., 2014), team (Manzi et al., 2010; Casamichana et al., 2013), aquatic (Wallace et al., 2009; Minganti et al., 2011a; Dellavalle and Haas, 2012) sports or in different modalities of strength and conditioning training such as, aerobic (Foster et al., 2001; Haddad et al., 2011a), intermittent (Foster et al., 2001; Haddad et al., 2011a), speed, plyometric, and resistance training (Singh et al., 2007; Alexiou and Coutts, 2008; Lockie et al., 2012) and tests (Herman et al., 2006; Haddad et al., 2011a). Table 2 presents an extensive database containing all studies (36 studies) that have analyzed the validity and reliability of the session-RPE method.

\section{SESSION-RPE METHOD: CORRELATIONS WITH OBJECTIVE MARKERS}

As presented in Table 2, the session-RPE method was correlated with several objective markers of TL. In the following section, mentioned objective markers in Table 2 are defined.

Bannister's training impulse (TRIMP) is a method used to quantify TL. It is calculated with a pre-evaluated coefficient obtained with the relationship between $\mathrm{HR}$ and blood lactate during an incremental exercise (y), multiplied with the HR reserve (HRres) and the duration of the sessions (t) (Banister, 1991). Its use was correlated to the session-RPE method during soccer training and match-, swimming-, basketball-, Taekwondo-, Australian football-, Canadian football-, rugby-, kayak sprinting-, karate training and match-, and fencing training and competing-sessions (Table 2).

Edwards' TRIMP is a method used for the calculation of TL with the time spent in five arbitrary HR zones multiplied by 


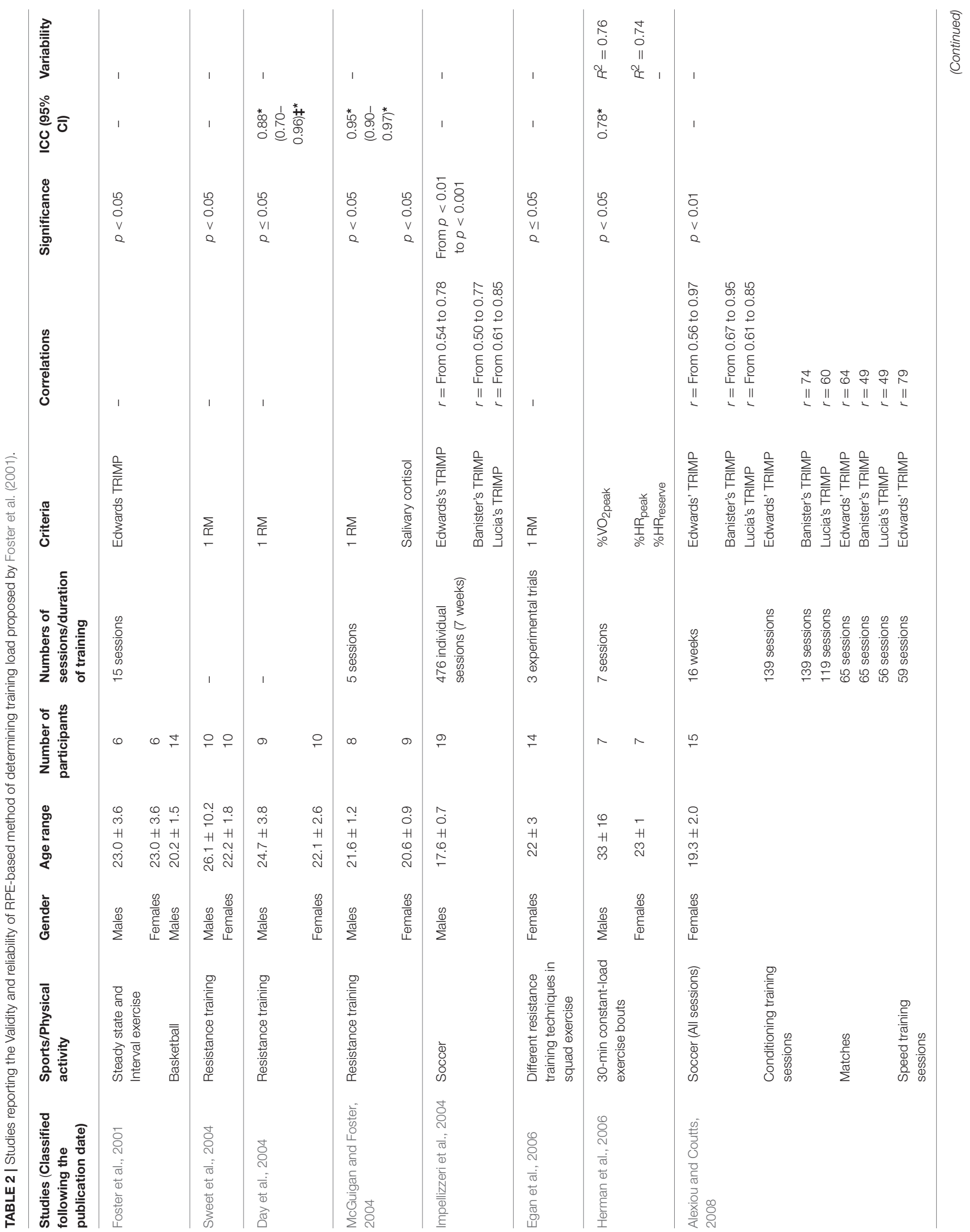




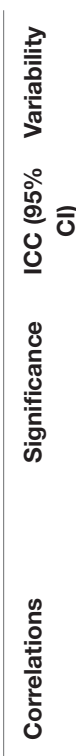

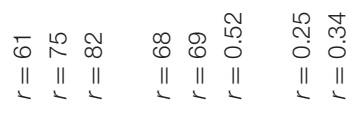
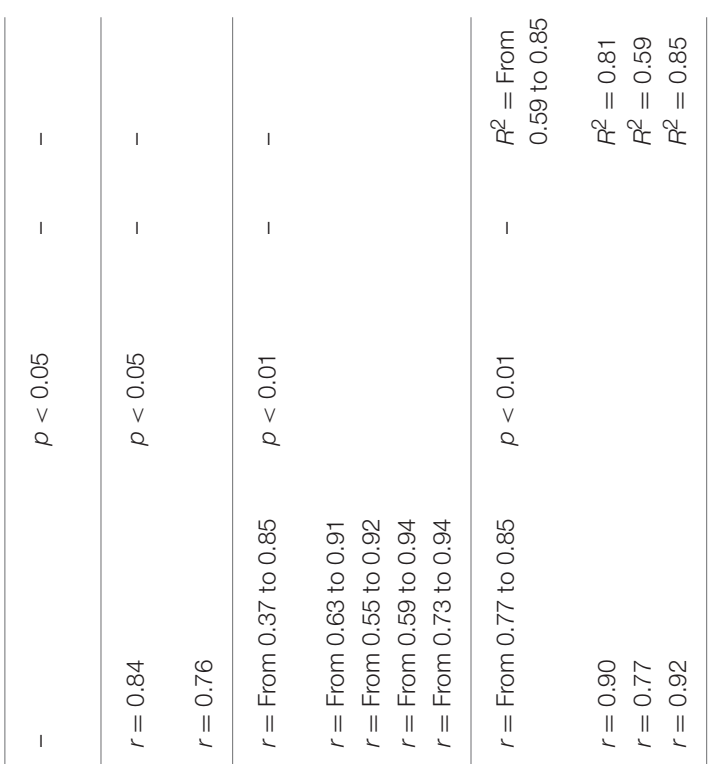

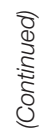
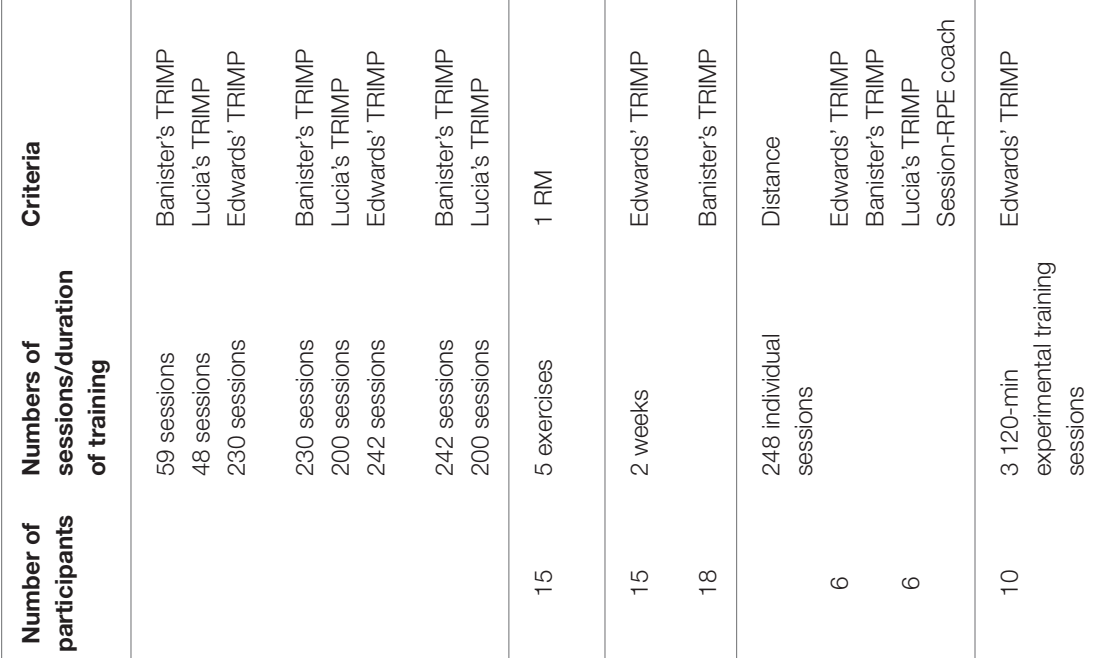

年
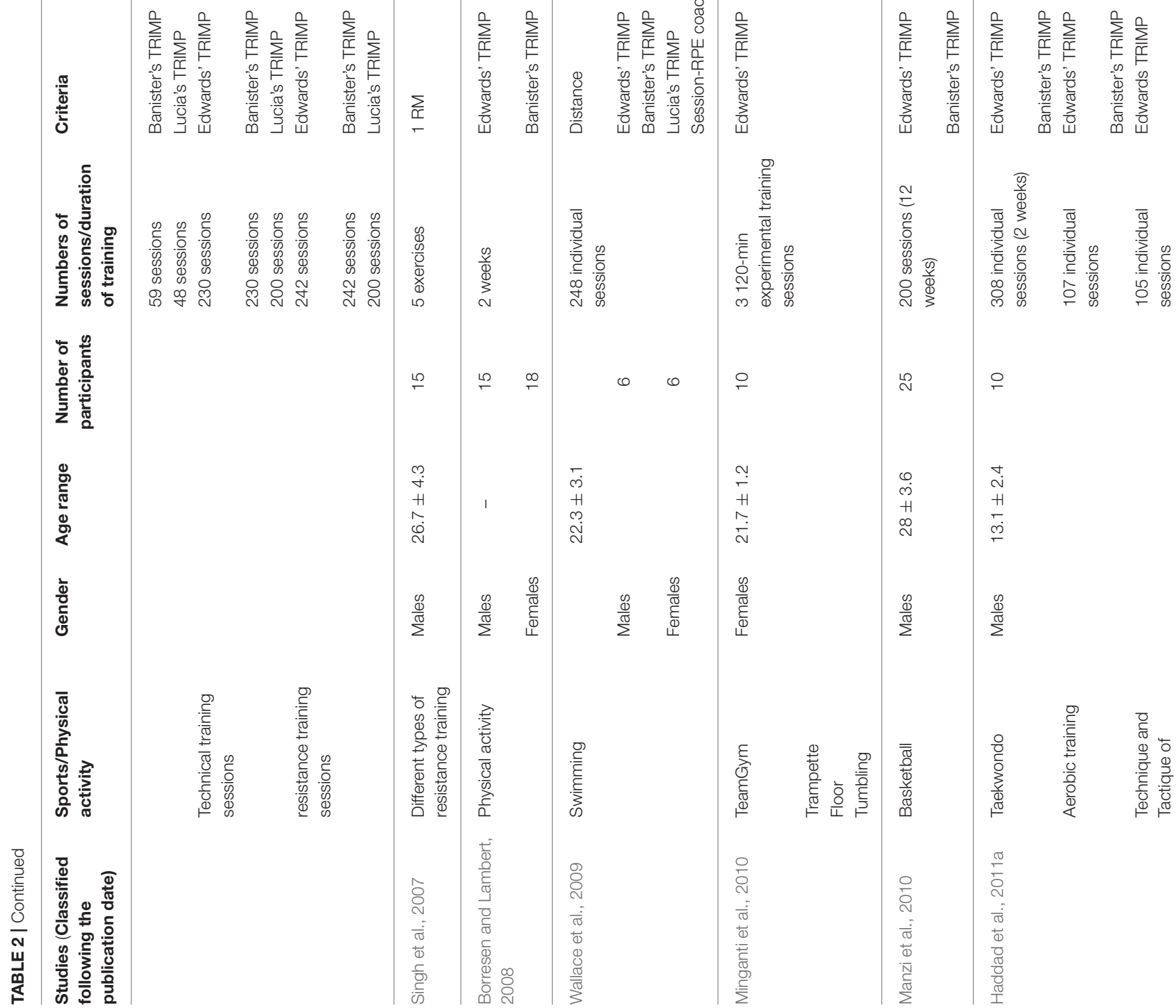


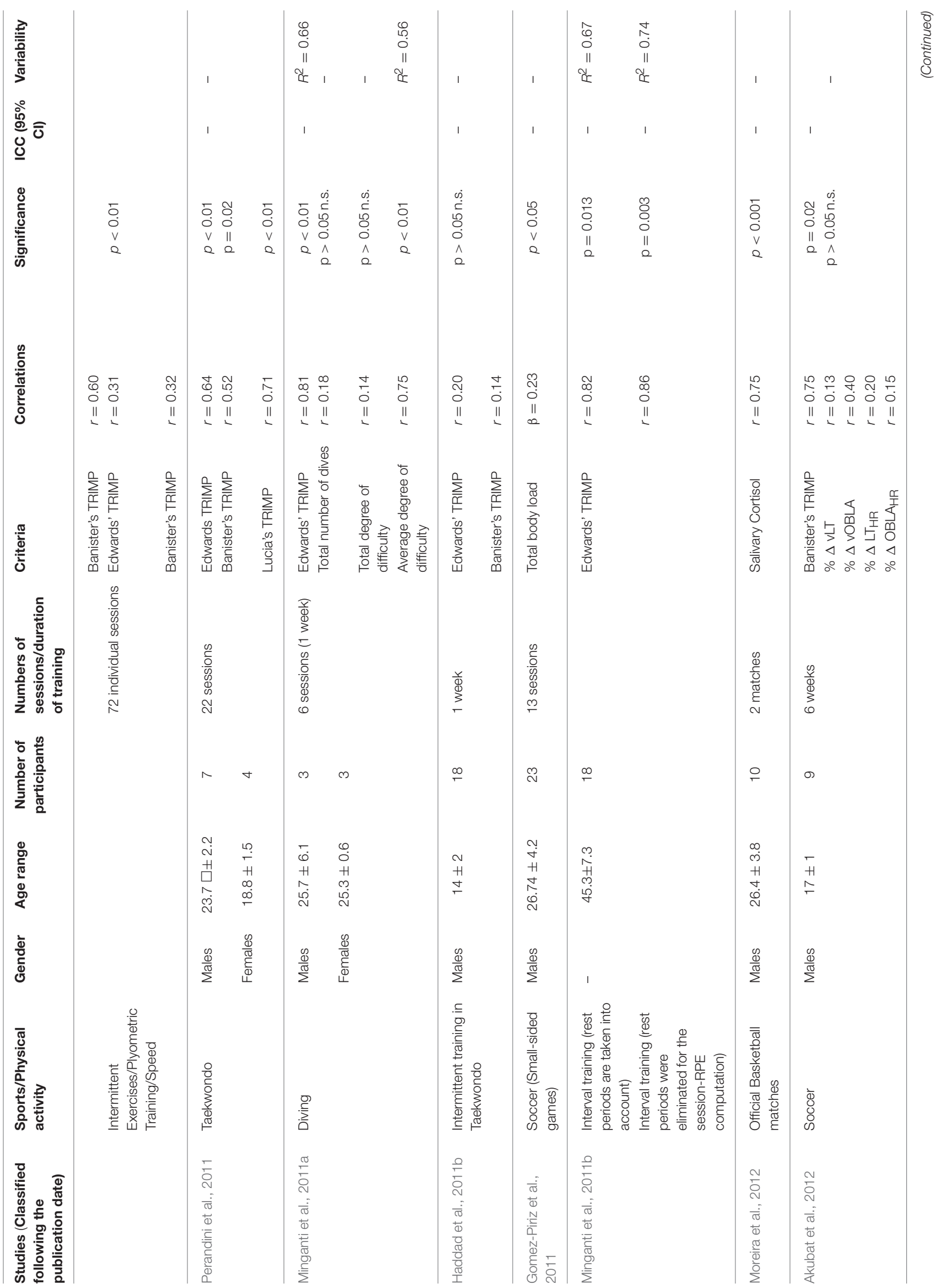




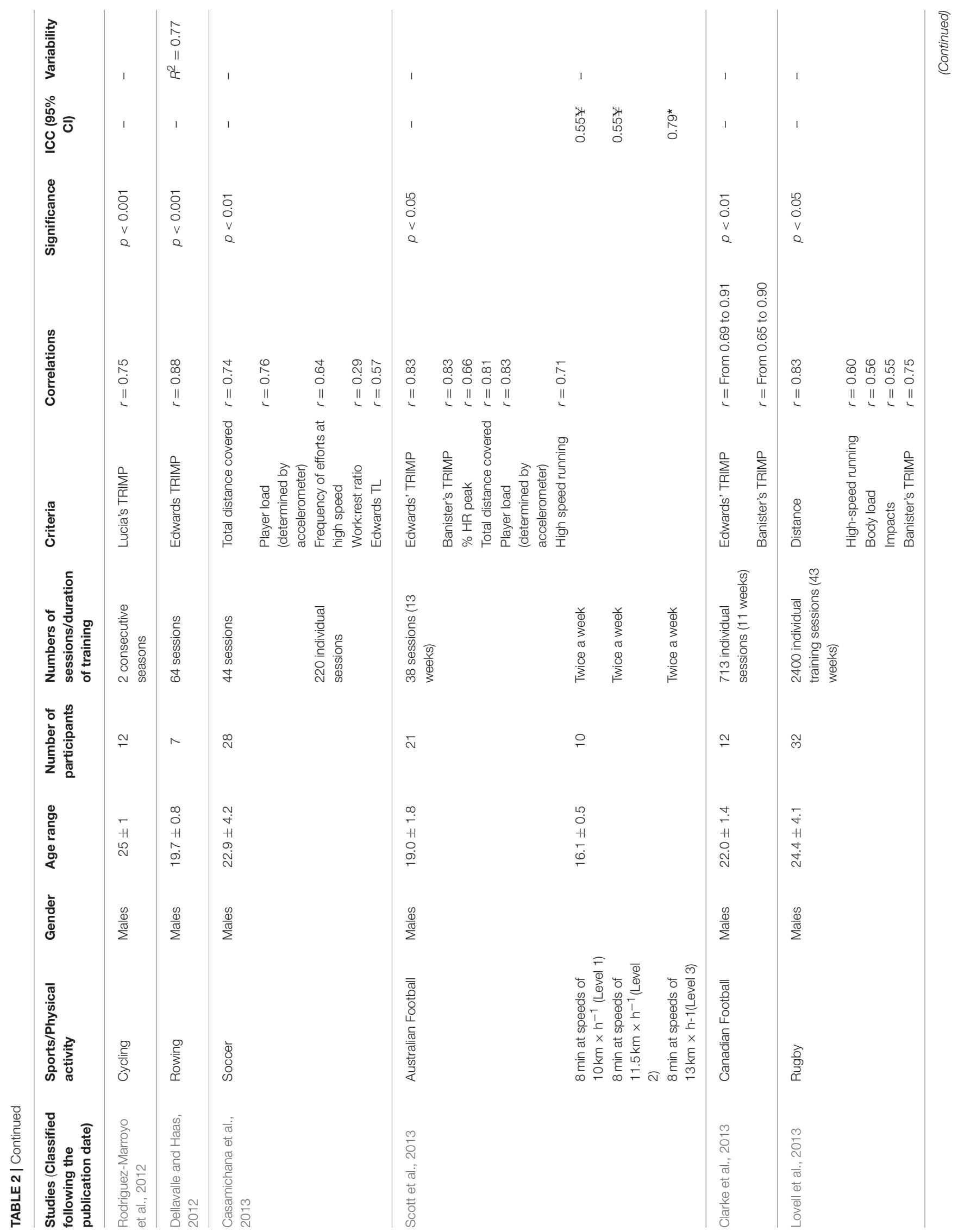




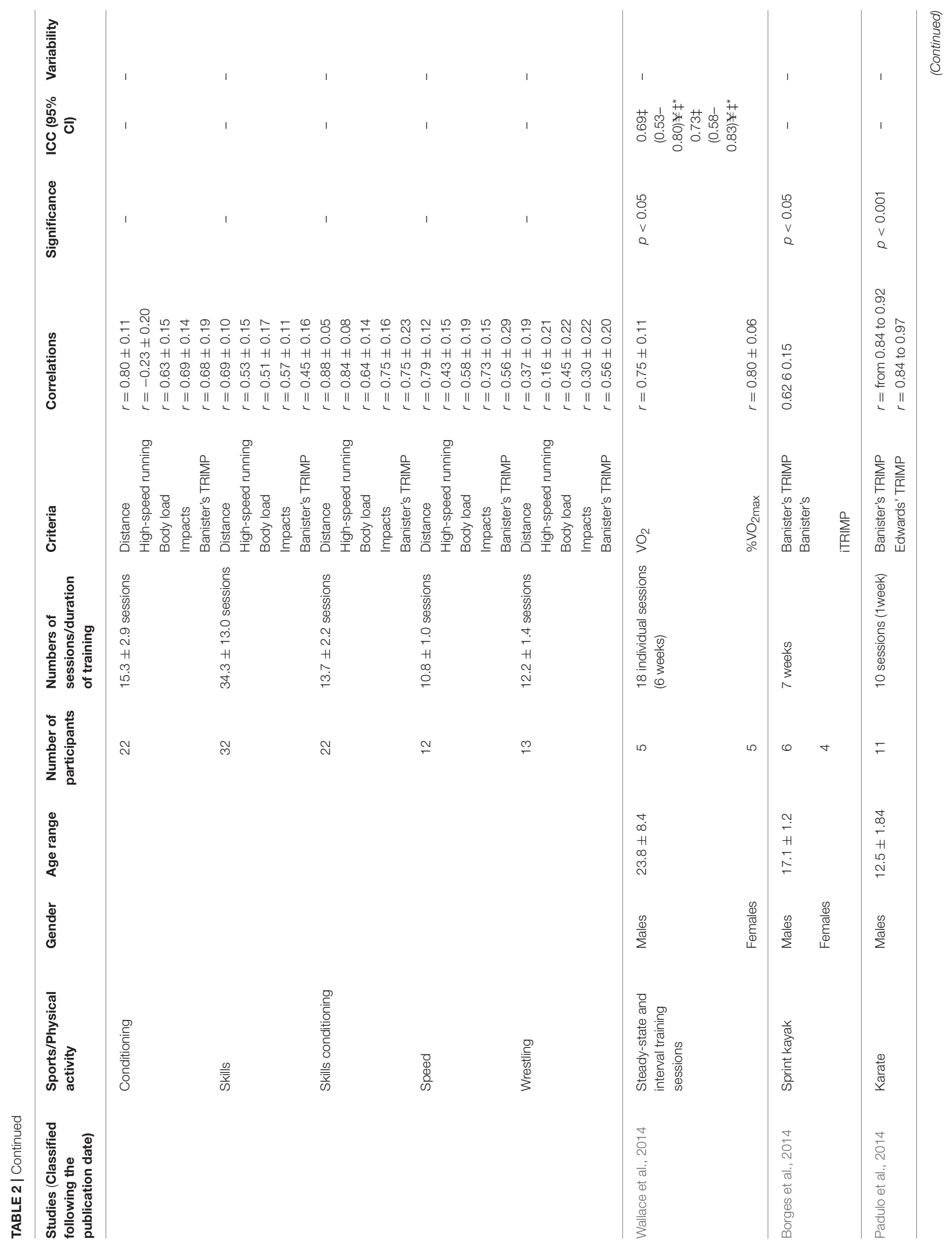




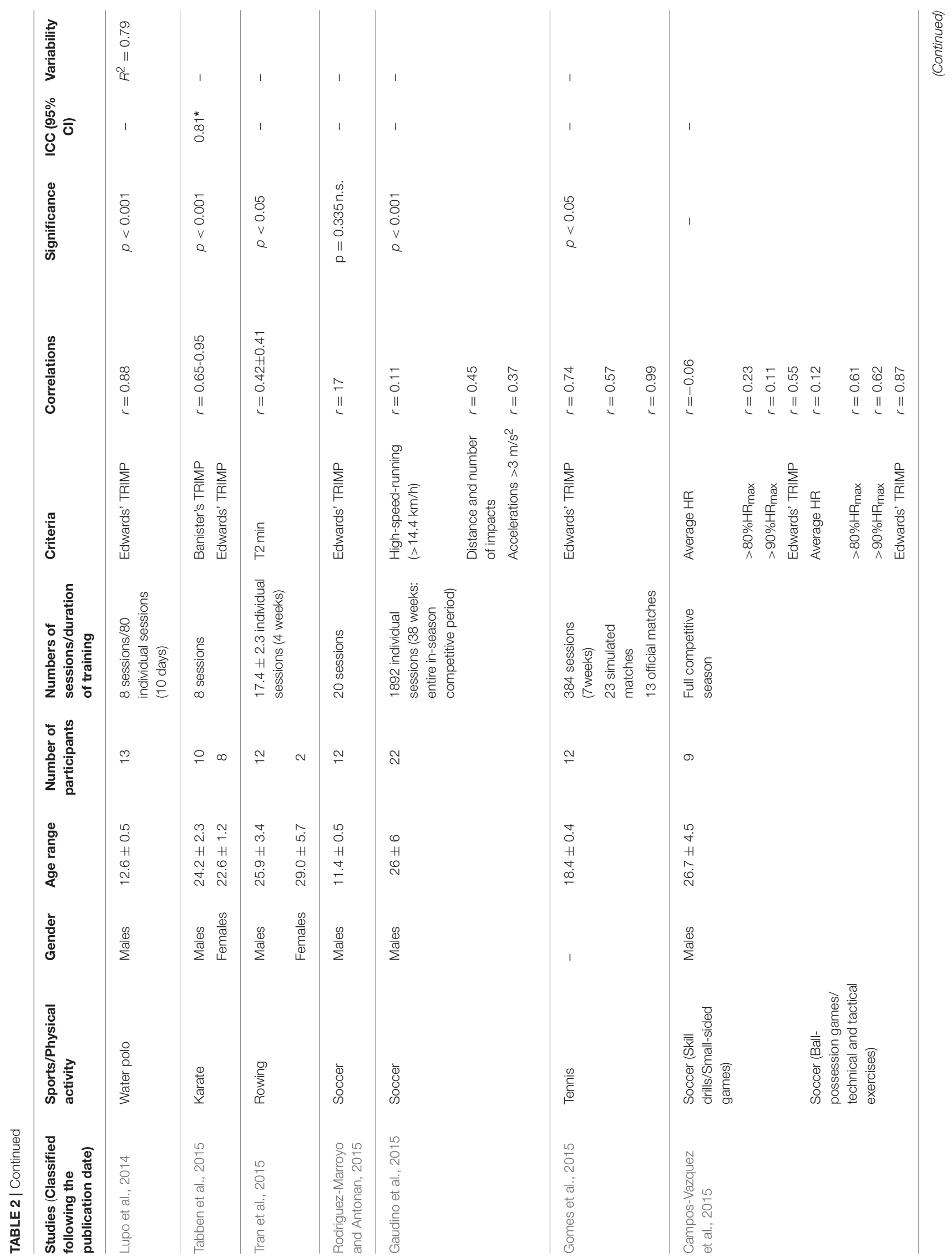




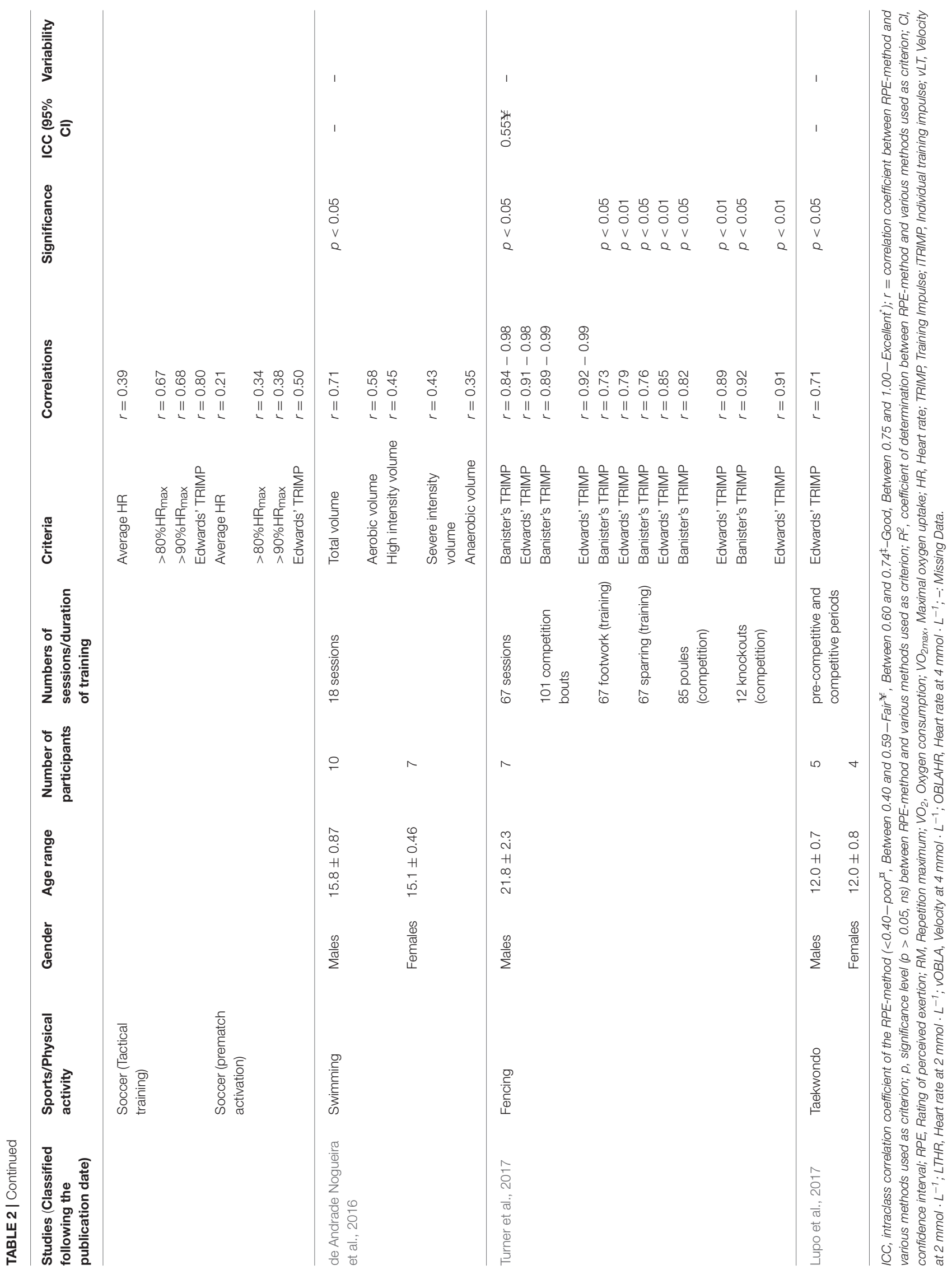


arbitrary coefficient $(>50-60 \% \mathrm{x} 1 ;>60-70 \% \times 2 ;>70-80 \% \times 3$; $>80-90 \% \times 4$; >90-100\% x5) (Edwards, 1993). This method was not validated with a known physiological response but was used in several studies as a good indicator of TL. Although, its use was correlated to the session-RPE method during soccer training and match-, swimming sessions, female fitness exercises, basketball, Taekwondo-, diving-, rowing-, Australian football-, Canadian football-, karate-, water polo-, tennis-, and fencing training and competing- sessions.

Lucia's TRIMP is also a method used to measure TL related to the ventilatory thresholds (VT1 and VT2). VT1 corresponds to the anaerobic threshold and VT2 to the respiratory compensation threshold. This method provides three zones: low ( $<\mathrm{VT} 1)$, moderate (VT1-VT2) and high ( $>\mathrm{VT} 2)$, and each zone corresponds to a coefficient: 1, 2, and 3 respectively. TL is calculated with the time spent in each zone multiplied by the corresponding coefficient, and added to each other (Lucia et al., 2003). Its use was correlated to the session-RPE method during soccer-, and swimming-training sessions.

HR is one of the most relevant objective markers of TL. It can be used with many forms to monitor TL and one of them is the percentage of maximal $\mathrm{HR}\left(\% \mathrm{HR}_{\max }\right)$ observed during exercise. Strong and very strong correlations were found between session-RPE method and $\% \mathrm{HR}_{\max }$ during soccer specific training sessions and during Australian football sessions for instance (Table 2).

The oxygen uptake during exercise $\left(\mathrm{VO}_{2}\right)$ and its expression as percentage of the maximal volume of oxygen uptake $\left(\% \mathrm{VO}_{2 \max }\right)$ were both strongly correlated to the session-RPE method for males and females practicing interval training.

Motion characteristics are frequently used to quantify TL, especially in team sport like rugby, Australian football and soccer, but also in individual sport like swimming as it provides individual information about the total distance covered or the distance covered in high speed displacement, for instance, during training and match.

Lactate threshold (LT) determination is one of the most relevant indicators of aerobic performance and training status. LT is where the pace has been raised to a point where Krebs cycle (aerobic energy), in muscle cells, cannot provide sufficient energy anymore. This threshold is usually observed at around $2 \mathrm{mmol} . \mathrm{l}^{-1}$. The second threshold, where a second increase in lactate accumulation happens around $4 \mathrm{mmol}^{-1}$ is referred to the onset of blood lactate threshold (OBLA). The velocity at LT (vLT) and OBLA (vOBLA) are the pace when running just before exceeding the LT and the OBLA point respectively. Their use was strongly correlated to the session-RPE method during soccer training sessions for instance (Table 2).

Some specific moves could also be assessed to quantify the TL, and each sport has its own related specific characteristics. Some of them were strongly correlated with session-RPE method, especially the number and the frequency of impacts in rugby, and the number and the level of difficulty of dives in diving, for instance (Table 2).

\section{SESSION-RPE METHOD: ECOLOGICAL USEFULNESS}

The session-RPE method might be used for monitoring one session, weekly blocks (mesocycle) and year-to-year periods (macrocycle) as well. Actually, it is widely recognized that the key of success for most athletes is the carefully periodization of different cycles throughout the training plan. The session-RPE method might provide a useful tool to better control the training periodization through monitoring all type of training sessions (Haddad et al., 2011a). Derived scores (i.e., Monotony and Strain) present useful complements to this method as explained above. Many authors have used the session-RPE method for monitoring training cycles such as Impellizzeri et al. (2004) and Akubat et al. (2012) in male Soccer, Alexiou and Coutts (2008) in female Soccer, Wallace et al. (2009) in Swimming, Manzi et al. (2010) in Basketball, Haddad et al. (2011a) in Taekwondo, Scott et al. (2013) in Rugby, and Padulo (Padulo et al., 2014) in Karate. The session-RPE method has also been used for monitoring entire macrocycles by Clarke et al. (2013) and Lovell et al. (2013) in Canadian football, by Murphy et al. (2014) in tennis, by Brink et al. (2014) in soccer and volleyball de Andrade Nogueira (de Andrade et al., 2014) in Volleyball.

The session-RPE method might allow achieving an appropriate TL periodization, therefore the likelihood of excessive TLs would be reduced. This might consecutively reduce the chances of overtraining or injury. Clarke et al. (2013) suggested that session-RPE method might help optimize physical development while minimizing overtraining, injury and illness across the board by enhancing awareness of individual responses to physical stimulus. For instance, application of the Session-RPE method can not only help to carefully manage the players back to full training but also to provide a valuable tool to begin investigating the relationship between training-load/fatigue and injuries (Chamari et al., 2012, 2013).

However, careful attention should be given to the relationship between prescribed/intended and perceived training. Basically, the coach will ask himself: "How will be the intended workload of the training session I'll prescribe?" using the same scale. As an example, the RPE of the coach is that the session intensity will be moderate which means 3 in the CR-10 scale. Athletes should answer a simple question: "How was your workout?" using this RPE scale after the training session. So, coaches and athletes are using the same scale to quantify the exercise intensity. Few studies have investigated the relation between the RPE of the coach (before the session) and the athlete (after the session). In summary, as one example of individual sports, Stewart and Hopkins (1997) showed a weak relationship between the coaches' prescribed intensity and the individual swimmer's perceived intensity. Wallace et al. (2009) showed that well-trained swimmers perceived their training sessions harder for high-intensity and lower for low-intensity training sessions than what was prescribed by the coach. This difference has been confirmed by other authors in individual sports such as Viveiros et al. (2011) in Judo and Murphy et al. (2014) in Tennis. The weak agreement between planned and perceived 
training dose of a coach and athlete/player was also observed during an entire season of team sports such Soccer (Brink et al., 2014) and volleyball (de Andrade et al., 2014). Brink et al. (2014) showed that the agreement between coaches' and players' perception of TL in a team sport appeared to be weaker in comparison with individual sports (Stewart and Hopkins, 1997; Wallace et al., 2009; Viveiros et al., 2011; Murphy et al., 2014). A logical explanation would be related to the difficulty for coaches to plan and control the exercise intensity for groups rather than individuals. Some solutions should be discovered in order to solve the inconsistencies between coaches prescribed and players perceived such as: (1) Throughout the scheduled training, coaches should keep in mind the specificity and individual characteristics (physical and psycho-social) that might affect the internal load of each individual player/athlete, (2) Use HR monitors to assist new RPE user to match their perceptions with the intensity of their training (Stagno et al., 2007). Controlling the relation between the scheduled and perceived TL of coaches and players/athletes respectively might improve performance by optimizing the TL periodization and preventing injuries and illnesses.

\section{FACTORS INFLUENCING PERCEIVED EXERTION}

It is well known that physiological and neural determinants do not fully explain the variation of RPE (Morgan, 1973) as other factors influence it as well. For instance, sociological factors such as the presence and the type of a co-actor at the moment of RPE collection in addition to personality factors (extraversion, neuroticism, depression, and anxiety) were shown to affect RPE (Morgan, 1973, 1994). Moreover subjects' characteristics such as gender, age, fitness level, and expertise level, might influence RPE as well. Other influences appear with environmental factors such as: listening to music, image and video watching, feedback and instructions about exercise, RPE scales' variation, hypnosis, environmental temperature, altitude, glycemia, the consumption of pharmacological and/or doping products, caffeine-, energy-, alcohol-, milk-chocolate-drinks, Ramadan fasting, and mobilization of attentional resources (Haddad et al., 2014b). Moreover, Haddad et al. (2014a) have suggested that the time spent at high-intensity and only marginally the session duration influenced the session' RPE. The same group has also shown that the reliability of an RPE-scale' translation in another language (other than English; French in that case) is affected despite keeping good internal consistency (Haddad et al., 2013a). However, the subjects' perception of

\section{REFERENCES}

Edwards, S. (ed.). (1993). "High performance training and racing" in The Heart Rate Monitor Book (Sacramento, CA: Feet Fleet Press), 113-123.

Akubat, I., Patel, E., Barrett, S., and Abt, G. (2012). Methods of monitoring the training and match load and their relationship to changes in fitness in professional youth soccer players. J. Sports Sci. 30, 1473-1480. doi: $10.1080 / 02640414.2012 .712711$ fatigue, stress, delayed onset muscle soreness, and sleep were not major contributors of RPE- for a $10 \mathrm{~min}$ sub-maximal effort during training with non-excessive TLs (Haddad et al., 2013b). This provides further evidence that RPE is not totally independent from efferent or afferent sensory signals. On the other hand, the influence of these factors could potentially be observed during high intensity training or overtraining. This still has to be investigated.

These various factors could somewhat alter the perception of exercise intensity; however, scientific literature supports the validity of RPE as indicator of exercise intensity despite any possible influence of contributing factors as described above. The good reliability and internal consistency of RPE in several sports and physical actives with men and women of different age categories (children, adolescents, and adults) among various expertise levels clearly shows the usefulness of the session-RPE method for efficient TL monitoring purposes (Haddad et al., 2014b).

\section{CONCLUSION}

Session-RPE method has been shown to be valid, reliable and very useful on the field. Nevertheless, other subjective measures also show high value. Coaches and staff cannot also exclude the possibility of adding to subjective measures, other objective measures (e.g., HR measures, adapted for endurance sports, and/or GPS measures, adapted for team) complementing even more the data obtained from subjective measures. Fine individualization is probably a key to training outcome optimization. In order to assess the status of the athlete before the training session, it would be interesting to complement the use of RPE with a "wellness index" (e.g., Hooper index or other tools). This would allow adapting the coming scheduled training session to the actual status of the athlete of that day in that particular moment.

\section{AUTHOR CONTRIBUTIONS}

$\mathrm{MH}$ conceived and designed the structure of the mini-review. All authors collected and analyzed the data. All authors drafted and approved the final version of the manuscript.

\section{FUNDING}

This publication was supported by Qatar University Student Grant QUST-2-CAS-2017-1. The findings achieved herein are solely the responsibility of the authors.

Alexiou, H., and Coutts, A. J. (2008). A comparison of methods used for quantifying internal training load in women soccer players. Int. J. Sports Physiol. Perform. 3, 320-330. doi: 10.1123/ijspp.3.3.320

Banister, E. W. (1991). "Modeling elite athletic performance," in Physiological Testing of Elite Athletes, eds H. Green, J. McDougal, H. Wenger (Champaign: Human Kinetics), 403-24.

Barry, B. K., and Enoka, R. M. (2007). The neurobiology of muscle fatigue: 15 years later. Integr. Comp. Biol. 47, 465-473. doi: 10.1093/icb/icm047

Borg, G. (1962). Physical Performance and Perceived Exertion. Sweden: Gleerup. 
Borges, T. O., Bullock, N., Duff, C., and Coutts, A. J. (2014). Methods for quantifying training in sprint kayak. J. Strength Cond. Res. 28, 474-482. doi: 10.1519/JSC.0b013e31829b56c4

Borresen, J., and Lambert, M. I. (2008). Quantifying training load: a comparison of subjective and objective methods. Int. J. Sports Physiol. Perform. 3, 16-30. doi: 10.1123/ijspp.3.1.16

Brink, M. S., Frencken, W. G., Jordet, G., and Lemmink, K. A. (2014). Coaches' and players' perceptions of training dose: not a perfect match. Int. J. Sports Physiol. Perform. 9, 497-502. doi: 10.1123/ijspp.2013-0009

Campos-Vazquez, M. A., Mendez-Villanueva, A., Gonzalez-Jurado, J. A., LeonPrados, J. A., Santalla, A., and Suarez-Arrones, L. (2015). Relationships between rating-of-perceived-exertion- and heart-rate-derived internal training load in professional soccer players: a comparison of on-field integrated training sessions. Int. J. Sports Physiol. Perform. 10, 587-592. doi: 10.1123/ijspp.2014-0294

Casamichana, D., Castellano, J., Calleja, J., Roman, J. S., and Castagna, C. (2013). Relationship between Indicators of Training Load in Soccer Players. J. Strength Cond. Res. 27, 369-374. doi: 10.1519/JSC.0b013e3182548af1

Chamari, K., Dellal, A., and Haddad, M. (2013). "Muscle injuries during ramadan," in Muscle Injuries, eds G. N. Bisciotti and C. Eirale (London: InTech).

Chamari, K., Haddad, M., Wong del, P., Dellal, A., and Chaouachi A. (2012). Injury rates in professional soccer players during Ramadan. J. Sports Sci. 30(Suppl. 1), S93-S102. doi: 10.1080/02640414.2012.696674

Clarke, N., Farthing, J. P., Norris, S. R., Arnold, B. E., and Lanovaz, J. L. (2013). Quantification of training load in Canadian football: application of sessionRPE in collision-based team sports. J. Strength Cond. Res. 27, 2198-2205. doi: 10.1519/JSC.0b013e31827e1334

Day, M. L., McGuigan, M. R., Brice, G., and Foster, C. (2004). Monitoring exercise intensity during resistance training using the session RPE scale. J. Strength Cond. Res. 18, 353-358. doi: 10.1519/r-13113.1

de Andrade Nogueira, F. C., de Freitas, V. H., Miloski, B., de Oliveira Cordeiro, A. H., Zacaron Werneck, F., Yuzo Nakamura, F., et al. (2016). Relationship between training volume and ratings of perceived exertion in swimmers. Percept. Motor Skills 122, 319-335. doi: 10.1177/0031512516629272

de Andrade, F. C., Nogueira, R. A., Coimbra, D. R., Dias, B. M., de Freitas, V. H., and Filho, M. B. (2014). Internal training load: perception of volleyball coaches and athletes. Rev. Bras. Cineantropom. Desempenho Hum. 16, 638-647. doi: 10.5007/1980-10.5007

Dellavalle, D. M., and Haas, J. D. (2012). Quantification of training load and intensity in female collegiate rowers: validation of a daily assessment tool. J. Strength Cond. Res. 27, 540-548. doi: 10.1519/JSC.0b013e31825 77053

Dempsey, J. A., Amann, M., Romer, L. M., and Miller, J. D. (2008). Respiratory system determinants of peripheral fatigue and endurance performance. Med. Sci. Sports Exerc. 40, 457-461. doi: 10.1249/MSS.0b013e31815f8957

Egan, A. D., Winchester, J. B., Foster, C., and McGuigan, M. R. (2006). Using session RPE to monitor different methods of resistance exercise. J. Sports Sci. Med. 5, 289-295.

Foster, C. (1998). Monitoring training in athletes with reference to overtraining syndrome. Med. Sci. Sports Exerc. 30, 1164-1168. doi: 10.1097/00005768-199807000-00023

Foster, C., Florhaug, J. A., Franklin, J., Gottschall, L., Hrovatin, L. A., Parker, S., et al. (2001). A new approach to monitoring exercise training. J. Proc. Natl. Acad. Sci. U.S.A. 15, 109-115. doi: 10.1519/00124278-200102000-00019

Gaudino, P., Iaia, F. M., Strudwick, A. J., Hawkins, R. D., Alberti, G., Atkinson, G., et al. (2015). Factors influencing perception of effort (session rating of perceived exertion) during elite soccer training. Int. J. Sports Physiol. Perform. 10, 860-864. doi: 10.1123/ijspp.2014-0518

Gomes, R. V., Moreira, A., Lodo, L., Capitani, C. D., Aoki, M. S., Foster, C., et al. (2015). Ecological Validity of Session RPE Method for Quantifying Internal Training Load in Tennis. Int. J. Sports Sci. Coaching 10, 729-737. doi: 10.1260/1747-9541.10.4.729

Gomez-Piriz, P. T., Jimenez-Reyes, P., and Ruiz-Ruiz, C. (2011). Relation between total body load and session rating of perceived exertion in professional soccer players. J. Strength Cond. Res. 25, 2100-2103. doi: 10.1519/JSC.0b013e3181fb4587

Haddad, M., Chaouachi, A., Castagna, C., Hue, O., Wong, D. P., Tabben, M., et al. (2013a). Validity and psychometric evaluation of the French version of RPE scale in young fit males when monitoring training loads. Sci. Sports 28, e29-e35 doi: 10.1016/j.scispo.2012.07.008

Haddad, M., Chaouachi, A., Castagna, C., Wong del, P., Behm, D. G., and Chamari, K. (2011a). The construct validity of session RPE during an intensive camp in young male Taekwondo athletes. Int. J. Sports Physiol. Perform. 6, 252-263. doi: 10.1123/ijspp.6.2.252

Haddad, M., Chaouachi, A., Wong del, P., Castagna, C., Hue, O., Impellizzeri, F. M., et al. (2014a). Influence of exercise intensity and duration on perceived exertion in adolescent Taekwondo athletes. Eur. J. Sport Sci. 14(Suppl. 1), S275-S281. doi: 10.1080/17461391.2012. 691115

Haddad, M., Chaouachi, A., Wong, D. P., Castagna, C., and Chamari, K. (2011b). Heart rate responses and training load during nonspecific and specific aerobic training in adolescent taekwondo athletes. J. Hum. Kinet. 29, 59-66. doi: 10.2478/v10078-0110040-y

Haddad, M., Chaouachi, A., Wong, D. P., Castagna, C., Hambli, M., Hue, O., et al. (2013b). Influence of fatigue, stress, muscle soreness and sleep on perceived exertion during submaximal effort. Physiol. Behav. 119, 185-189. doi: 10.1016/j.physbeh.2013.06.016

Haddad, M., Padulo, J., and Chamari, K. (2014b). The usefulness of session rating of perceived exertion for monitoring training load despite several influences on perceived exertion. Int. J. Sports Physiol. Perform. 9, 882-883. doi: 10.1123/ijspp.2014-0010

Hamilton, A. L., Killian, K. J., Summers, E., and Jones, N. L. (1985). Quantification of intensity of sensations during muscular work by normal subjects. J. Appl. Physiol. 81, 1156-1161.

Herman, L., Foster, C., Maher, M. A., Mikat, R. P., and Porcari, J. P. (2006). Validity and reliability of the session RPE method for monitoring exercise training intensity: original research article. S Afr. J. Sports Med. 18, 14-17. doi: 10.17159/2078-516X/2006/v18ila247

Impellizzeri, F. M., Rampinini, E., Coutts, A. J., Sassi, A., and Marcora, S. M. (2004). Use of RPE-based training load in soccer. Med. Sci. Sports Exerc. 36, 1042-1047. doi: 10.1249/01.MSS.0000128199.23901.2F

Lockie, R. G., Murphy, A. J., Scott, B. R., and Janse de Jonge, X. A. (2012). Quantifying session ratings of perceived exertion for field-based speed training methods in team sport athletes. J. Strength Cond. Res. 26, 2721-2728. doi: 10.1519/JSC.0b013e3182429b0b

Lovell, T. W., Sirotic, A. C., Impellizzeri, F. M., and Coutts, A. J. (2013). Factors affecting perception of effort (session rating of perceived exertion) during rugby league training. Int. J. Sports Physiol. Perform. 8, 62-69. doi: 10.1123/ijspp.8.1.62

Lucia, A., Hoyos, J., Santalla, A., Earnest, C., and Chicharro, J. L. (2003). Tour de France versus Vuelta a Espana: which is harder? Med. Sci. Sports Exerc. 35, 872-878. doi: 10.1249/01.MSS.0000064999.82036.B4

Lupo, C., Capranica, L., Cortis, C., Guidotti, F., Bianco, A., and Tessitore, A. (2017). Session-RPE for quantifying load of different youth taekwondo training sessions. J. Sports Med. Phys. Fitness. 57, 189-194. doi: 10.23736/S0022-4707.16.06021-X

Lupo, C., Capranica, L., and Tessitore, A. (2014). The validity of the sessionRPE method for quantifying training load in water polo. Int. J. Sports Physiol. Perform. 9, 656-660. doi: 10.1123/ijspp.2013-0297

Manzi, V., D’Ottavio, S., Impellizzeri, F. M., Chaouachi, A., Chamari, K., and Castagna, C. (2010). Profile of weekly training load in elite male professional basketball players. J. Strength Cond. Res. 24, 1399-1406. doi: 10.1519/JSC.0b013e3181d7552a

Marcora, S. (1985). Perception of effort during exercise is independent of afferent feedback from skeletal muscles, heart, and lungs. J. Appl. Physiol. 106, 2060-2062. doi: 10.1152/japplphysiol.90378.2008

McGuigan, M. R., and Foster, C. (2004). A new approach to monitoring resistance training. Strength Cond. J. 26:42. doi: 10.1519/00126548-200412000-00008

Minganti, C., Capranica, L., Meeusen, R., Amici, S., and Piacentini, M. F. (2010). The validity of sessionrating of perceived exertion method for quantifying training load in teamgym. J. Strength Cond. Res. 24, 3063-3068. doi: 10.1519/JSC.0b013e3181cc26b9

Minganti, C., Capranica, L., Meeusen, R., and Piacentini, M. F. (2011a). The use of session-RPE method for quantifying training load in diving. Int. J. Sports Physiol. Perform. 6, 408-418. doi: 10.1123/ijspp.6.3.408 
Minganti, C., Ferragina, A., Demarie, S., Verticchio, N., Meeusen, R., and Piacentini, M. F. (2011b). The use of session RPE for interval training in master endurance athletes: should rest be included? J. Sports Med. Phys. Fitness 51, $547-554$.

Moreira, A., McGuigan, M. R., Arruda, A. F., Freitas, C. G., and Aoki, M. S. (2012). Monitoring internal load parameters during simulated and official basketball matches. J. Strength Cond. Res. 26, 861-866. doi: 10.1519/JSC.0b013e31822645e9

Morgan, W. P. (1973). Psychological factors influencing perceived exertion. Med. Sci. Sports 5, 97-103. doi: 10.1249/00005768-197300520-00019

Morgan, W. P. (1994). Psychological components of effort sense. Med. Sci. Sports 26, 1071-1077. doi: 10.1249/00005768-19940900000001

Murphy, A. P., Duffield, R., Kellett, A., and Reid, M. (2014). Comparison of athlete-coach perceptions of internal and external load markers for elite junior tennis training. Int. J. Sports Physiol. Perform. 9, 751-756. doi: 10.1123/ijspp.2013-0364

Padulo, J., Chaabene, H., Tabben, M., Haddad, M., Gevat, C., Vando, S., et al. (2014). The construct validity of session RPE during an intensive camp in young male Karate athletes. Muscles Ligaments Tendons J. 4, 121-126. doi: $10.11138 / \mathrm{mltj} / 2014.4 .2 .121$

Perandini, L. A., Siqueira-Pereira, T. A., Okuno, N. M., Soares-Caldeira, L. F., and Nakamura, F. Y. (2011). Use of session RPE to training load quantification and training intensity distribution in taekwondo athletes. Sci. Sports 27, e25-e30. doi: 10.1016/j.scispo.2011.07.001

Pollak, K. A., Swenson, J. D., Vanhaitsma, T. A., Hughen, R. W., Jo, D., White, A. T., et al. (2014). Exogenously applied muscle metabolites synergistically evoke sensations of muscle fatigue and pain in human subjects. Exp. Physiol. 99, 368-380. doi: 10.1113/expphysiol.2013.075812

Putlur, P., Foster, C., Miskowski, J, A., Kane, M, K., Burton, S, E., Scheett, T, P., et al. (2004). Alteration of immune function in women collegiate soccer players and college students J. Sports Sci. Med. 3, 234-243.

Proske, U. (2005). What is the role of muscle receptors in proprioception? Muscle Nerve 31, 780-787. doi: 10.1002/mus.20330

Rodriguez-Marroyo, J. A., and Antonan, C. (2015). Validity of the session rating of perceived exertion for monitoring exercise demands in youth soccer players. Int. J. Sports Physiol. Perform. 10, 404-407. doi: 10.1123/ijspp.201 4-0058

Rodriguez-Marroyo, J. A., Villa, G., Garcia-Lopez, J., and Foster, C. (2012). Comparison of heart rate and session rating of perceived exertion methods of defining exercise load in cyclists. J. Strength Cond. Res. 26, 2249-2257. doi: 10.1519/JSC.0b013e31823a4233

Scott, T. J., Black, C., Quinn, J., and Coutts, A. J. (2013). Validity and reliability of the session RPE method for quantifying training in Australian Football: a comparison of the CR10 and CR100 scales. J. Strength Cond. Res. 27, 270-276. doi: 10.1519/JSC.0b013e3182541d2e

Singh, F., Foster, C., Tod, D., and McGuigan, M. R. (2007). Monitoring different types of resistance training using session rating of perceived exertion. Int. J. Sports Physiol. Perform. 2, 34-45. doi: 10.1123/ijspp.2.1.34
Stagno, K. M., Thatcher, R., and van Someren, K. A. (2007). A modified TRIMP to quantify the in-season training load of team sport players. J. Sports Sci. 25, 629-634. doi: 10.1080/02640410600811817

Stewart, A. M., and Hopkins, W. G. (1997). Swimmers' compliance with training prescription. Med. Sci. Sports Exerc. 29, 1389-1392. doi: 10.1097/00005768-199710000-00018

Sweet, T. W., Foster, C., McGuigan, M. R., and Brice, G. (2004). Quantitation of resistance training using the session rating of perceived exertion method. $J$. Strength Cond. Res. 18, 796-802. doi: 10.1519/14153.1

Tabben, M., Sioud, R., Haddad, M., Franchini, E., Chaouachi, A., Chamari, K., et al. (2013). Physiological and Perceived Exertion Responses during International Karate Kumite Competition. Asian J. Sports Med. 4, 263-271. doi: 10.5812/asjsm.34246

Tabben, M., Tourny, C., Haddad, M., Chaabane, H., Chamari, K., and Coquart, J. B. (2015). Validity and reliability of the session-RPE method for quantifying training load in karate athletes. J. Sports Med. Phys. Fitness. doi: 10.1249/01.mss.0000477429.41094.00. [Epub ahead of print].

Tran, J., Rice, A. J., Main, L. C., and Gastin, P. B. (2015). Convergent validity of a novel method for quantifying rowing training loads. J. Sports Sci. 33, 268-276. doi: 10.1080/02640414.2014.942686

Turner, A. N., Buttigieg, C., Marshall, G., Noto, A., Phillips, J., and Kilduff, L. (2017). Ecological validity of the session rpe method for quantifying internal training load in fencing. Int. J. Sports Physiol. Perform. 12, 124-128. doi: 10.1123/ijspp.2016-0062

Viveiros, L., Costa, E., Moreira, A., Nakamura, F., and Aoki, M. (2011) Training load monitoring in judo: comparison between the training load intensity planned by the coach and the intensity experienced by the athlete. Rev. Bras. Med. Esporte 17, 266-269. doi: 10.1590/S1517-869220110004 00011

Wallace, L. K., Slattery, K. M., and Coutts, A. J. (2009). The ecological validity and application of the session-RPE method for quantifying training loads in swimming. J. Strength Cond. Res. 23, 33-38. doi: 10.1519/JSC.0b013e3181874512

Wallace, L. K., Slattery, K. M., Impellizzeri, F. M., and Coutts, A. J. (2014). Establishing the criterion validity and reliability of common methods for quantifying training load. J. Strength Cond. Res. 28, 2330-2337. doi: 10.1519/JSC.0000000000000416

Conflict of Interest Statement: The authors declare that the research was conducted in the absence of any commercial or financial relationships that could be construed as a potential conflict of interest.

Copyright (c) 2017 Haddad, Stylianides, Djaoui, Dellal and Chamari. This is an open-access article distributed under the terms of the Creative Commons Attribution License (CC BY). The use, distribution or reproduction in other forums is permitted, provided the original author(s) or licensor are credited and that the original publication in this journal is cited, in accordance with accepted academic practice. No use, distribution or reproduction is permitted which does not comply with these terms. 